\title{
Toda música (séria) é alemã? - Prelúdio de uma geopolítica da música ${ }^{1}$
}

\author{
Paulo Masella
}

\section{Resumo}

A partir da análise do formalismo de Adorno e do espírito trágico de Nietzsche, em suas respectivas considerações teóricas sobre a música, levantase a hipótese de que estas tracem linhas de força expressivas, imanentes ao contexto territorial e cultural de sua produção e escuta, desenhando uma geopolítica que poderia resultar na proposição de uma matriz epistemológica espacial na construção de sentido estético. As evidências que sustentariam essa hipótese encontram-se nas constantes inferências que esses autores fazem ao caráter universal da música supostamente contido no "espírito alemão", confundindo suas posições epistemológicas com as fronteiras territoriais de suas culturas.

\section{Palavras-Chave}

Estética. Epistemologia. Cultura.
Paulo Masella | paulomasella@usp.br Doutorando e mestre em Ciências da Comunicação pela Escola de Comunicação e Artes da Universidade de São Paulo [ECA-USP]. Bacharel em Filosofia pela Faculdade de Filosofia, Ciências e Letras da Universidade de São Paulo [FFLCH-USP].

\section{Referenciais epistemológicos das estéticas}

Ainda que se possa discutir se as inúmeras teorias que alimentam 0 campo da comunicação seriam ou não adequadas à pesquisa de seu volátil objeto, parece indubitável supor que 0 aporte de teorias estéticas ao campo não seja apenas restrito como vinculado a epistemologias que se colocam a serviço de grandes sistemas de pensamento filosófico, como encontramos em Platão, Aristóteles, Kant e Hegel, que, por sua vez, orientam as investigações atuais dos chamados "objetos artísticos". Um caso exemplar reside na Introdução à sociologia da música de Theodor Adorno, cuja abordagem estética de seu objeto tanto se ancora na teoria crítica, como herda da dialética hegeliana parte significativa de seus pressupostos epistemológicos.

Referência inconteste nos estudos em comunicação, como se observa pela sua frequente adoção ou veemente recusa, a teoria crítica extrai sua força conceitual e epistemológica da tradição filosófica, com um acento preciso na 
dialética histórica, que viria a ser contestada pelo estruturalismo e pela filosofia analítica ao subverteram 0 eixo diacrônico pelo sincrônico na análise de produção de sentido, colocando a linguagem - e não o pensamento reflexivo no centro das discussões epistemológicas. 0 que talvez passe despercebido seja que essas epistemologias desenham uma espécie de mapa geopolítico, cujo caráter gráfico não é apenas ilustrativo, mas representativo das suas condições de produção. Que 0 estruturalismo fale francês e a teoria crítica pense em alemão evidentemente não traduz literalmente suas proposições teóricas, mas podem constituir linhas de força expressivas que revelem suas condições culturais - e não necessariamente linguísticas - de produção.

Se a dialética histórica admite um movimento de transformação temporal de sentido, não haveria por que não supor que esse movimento também possa ser espacial, dobrando-se inclusive sobre si mesmo. Se a dialética histórica tende a se exercer por um movimento unívoco - teleológico ou não -, e reivindicar uma lógica universal, as linhas de forças expressivas espaciais tendem à pluralidade e ao privilégio dos particulares. Tomando como referência a linguística, a antropologia estrutural já enfatizara esses aspectos na análise sincrônica de seus objetos, repercutindo na antropologia cultural e na semiótica da cultura, o que, por si só, desfaz qualquer aventureirismo dessa hipótese. Em sua defesa, parte-se da suposição de uma concepção geopolítica da música que se evidenciaria a partir da análise de fragmentos das obras de Adorno e Nietzsche que parecem enfatizar esse aspecto territorial que a música assume nos seus modos de produção e escuta.

\section{0 sentido da música em sua linguagem}

Em uma primeira mirada, talvez cause certo estranhamento admitir que exista uma imbricação entre a teoria crítica, herdeira da tradição filosófica, e o formalismo na música, quando este parece se refugiar numa estrutura cuja lógica interna prescinde de uma fundamentação no real, que se constitui justamente num dos pilares ontológicos daquela. Todavia, é o que Adorno propõe ao conceder à música uma autonomia, supondo uma espécie de autodeterminação do signo musical, que implica em libertá-lo das contradições do seu modo de produção tal como o conceito se abstrai do concreto no processo de produção de ideologia, criando uma relação paradoxal entre as pesadas atribuições disciplinadoras do logos e a irresponsabilidade política do signo. Quando Adorno (2011, p. 60) define 0 expert como 0 tipo mais adequado de comportamento musical, capaz de uma "escuta estrutural", cujo horizonte é "a lógica musical concreta", lógica essa que revela seu sentido por

Ensaio produzido a partir do artigo A música tensionada entre a logosfera e a semiosfera, apresentado ao GT de Epistemologia do XXI Compós, em junho de 2012. 0 presente trabalho foi realizado com apoio do CNPq, Conselho Nacional de Desenvolvimento Científico e Tecnológico - Brasil. 
categorias técnicas, por um lado ele cumpre com as determinações do logos ao afirmar que há uma música verdadeira e "séria", mas, por outro lado, ele sugere um descolamento do sentido da música dos meios de produção social para fixá-lo na estrutura interna da notação musical, libertando-o de seu viés ideológico. 0s rastros que Adorno deixa desse possível paradoxo encontramse também em sua Filosofia da nova música que teria em Schoenberg sua figura mais eminente. Em Schoenberg, a "vontade de verdade" do logos se encontra com as leis que regem a sintaxe musical. "Schoenberg introduz, por uma espécie de golpe de estado, a música no reino do conhecimento, concedendo uma importância essencial à linguagem, e isso nos mesmos anos em que a filosofia da 'guinada linguística' toma impulso" (SOULEZ, 2007, p. 284).

Essa autonomização da música já havia sido esboçada por Hanslick "ao defender a concepção segundo a qual as ideias musicais constituem um belo independente, esteticamente autônomo", estabelecendo as bases do formalismo (VIDEIRA, 2007, p. 151). 0 conceito entendido como signo, e não como palavra, passa a dar materialidade à música, colocando em discussão não só a pertinência de seu atravessamento ideológico como a centralidade do sentimento na representação de seus conteúdos e seus efeitos sobre a audiência.

A posição de Hanslick de que os sentimentos não se constituem em conteúdo ou objeto da música encontra ressonância em Schoenberg que, por sua vez, é acolhida por Adorno (2011, p. 60-75) quando deixa claro que a questão do sentimento na música deve ser afastada. Em sua tipologia, o expert e, em alguma medida, o "bom ouvinte" são aqueles que podem decifrar os códigos e que, portanto, colocam-se como decodificadores da complexa sintaxe da "música séria". Se 0 expert "ao seguir espontaneamente 0 curso de uma música intrincada, [...] escuta a sequência de instantes passados, presentes e futuros de modo tão contíguo que uma interconexão de sentido se cristaliza", o bom ouvinte "compreende a música tal como se compreende em geral a própria linguagem mesmo que desconheça ou nada saiba sobre sua gramática ou sintaxe, ou seja, dominando inconscientemente a lógica musical imanente". Já o "ouvinte emocional" - aquele que "é fácil fazê-lo chorar" - é o que se deixa levar por "[...] excitações instintivas reprimidas ou domadas pelas normas civilizatórias, convertendo-se em uma fonte variegada de irracionalidade", ainda que esteja acima do "ouvinte do entretenimento" que "[...] é aquele pelo qual se calibra a indústria cultural". Ou seja, a complexidade na codificação da estrutura musical e sua adequada decodificação constituem-se no modo da música permanecer a salvo da ideologia, não se deixando levar pela fraqueza do sensível em perceber e criticar os interesses do mercado.

Em outra linhagem, Nietzsche também parece concordar que a música não deve ilustrar nada, não se subordinando nem aos sentimentos - já 
demasiadamente saturados de signos - muito menos ao conceito, que jamais expressa a singularidade do vivido, mantendo-se em um momento pré-sígnico, anterior inclusive à vontade, a qual a música tem por objeto, mas não deve sua origem. Em 0 Nascimento da Tragédia, a música é da ordem da audição, do dionisíaco, anterior à ordem da visão, das imagens e dos conceitos que 0 apolíneo, o racional, introduz. Todavia, essa perspectiva encontra-se distante de uma visão formalista da música como a encontramos em Schoenberg e Adorno, pois, Nietzsche entende a música como "forma de arte capaz de expressar um conteúdo de experiência inacessível à linguagem", tornando "comunicáveis impressões para as quais não se encontram palavras e que escapam das formas e categorias da linguagem" (CAVALCANTI, 2007, p. 186), pressupondo não uma autonomia da forma musical, mas uma anterioridade pré-cognitiva que se coloca na ordem do indizível ou intraduzível.

\footnotetext{
A imagem, diferentemente da música, jamais pode expressar com clareza o "ilimitado" da experiência dionisíaca, tudo o que é aí sentido e experimentado. A relação que caracteriza as imagens e a melodia não é de correspondência, mas uma relação simbólica. [...] A palavra é impotente diante de certos conteúdos da experiência, pois é composta de um conjunto de signos preestabelecidos; ela tende a fixar em unidade e forma o movimento e a diversidade do pensamento. Mas esse limite estimula a linguagem a avançar, repetir o que foi dito, na busca de uma forma de expressão capaz de abarcar não somente o que se tornou claro, mas o "resto" sempre remanescente, próprio ao estado que antecede à linguagem. (CAVALCANTI, 2007, p. 188)
}

Como lembra Videira (2007, p. 164), Webern e

Stravinsky, alinhados ao modernismo na música, também repudiam o ouvinte que se remete constantemente a imagens para seguir a música, incapazes de entendê-la em sua estrutura musical, mas se nesses casos o signo musical deve manter-se puro, em Nietzsche, a música deve ser ouvida em sua dimensão trágica, em sua unidade cósmica, pré-sígnica.

Em uma operação que remete ao marco zero da epistemologia ao promover uma cisão entre percepção e intelecção, a música se descola do plano do sensível para se situar no plano do inteligível, cumprindo o ideal platônico de manter o conceito livre das ilusões provocadas pelos sentidos e das opiniões. Para Adorno (2011, p. 120-121), a música não chega a ser conceitual, mas se aproxima muito disso ao admitir que seja "uma linguagem, mas sem conceitos".

Imaterial, a música não pode identificar-se univocamente com nenhum dos momentos do mundo exterior, mas ao mesmo tempo, acha-se extremamente articulada e determinada em si mesma, e, com isso, torna-se uma vez mais algo comensurável em relação ao mundo exterior e à realidade social, ainda que seja veiculada dessa forma. (ADORNO, 2011, p. 120).

\section{É justamente esse caráter imaterial e não} exatamente conceitual da música que dificulta 0 estabelecimento de relações mais diretas com as classes sociais, tornando-a ideologicamente ainda mais eficaz. Diferenciando-se de uma perspectiva platônica, a operação epistemológica que permite 
à música distanciar-se da materialidade dos objetos e da experiência sensória que culmina em representações consiste na diferenciação entre formalização e conceitualização.

Na procura por uma forma racional capaz de fornecer determinação adequada àquilo que é "qualitativamente contrário ao conceito", Adorno encontra na música um horizonte privilegiado, mesmo em relação às outras artes. Neste sentido, ele não é o primeiro: Adorno partilha e desdobra uma tradição que vê no caráter não figurativo da música instrumental desprovida de funções, de programas e de textos - música que a estética do romantismo alemão chamará de "música absoluta" - 0 veículo privilegiado para a exposição daquilo que excede a determinação conceitual. (SAFATLE, 2007, p. 372-373).

A problemática adquire uma configuração complexa, pois ao mesmo tempo em que Adorno, conservando-se na tradição filosófica, confere à inteligibilidade da música a necessidade em se manter dentro de um processo de representação que não pode negar o social, aproxima-se de uma perspectiva estruturalista em que a forma absorve os planos da expressão e do conteúdo na busca de uma autonomia que prescindiria do recurso mimético de modelização do real, alojando-se numa estrutura lógica e interna de sentido.

Na trilha de Hanslick, Adorno concebe a forma não como recipiente de um conteúdo a ser preenchido por matérias sonoras ou sentimentos musicais, mas como uma totalidade racional que absorve a harmonia, melodia, ritmo, texturas e frases de forma expressiva, enquanto Schoenberg pensa que a música, como a arte, não deva visar o belo senão a verdade, cuja lógica da composição expressaria o "eidos formal da sintaxe do sonoro" (SOULEZ, 2007, p. 284). A união de forma e ideia, estética e ética, remeteria a um idealismo platônico não fosse Adorno fiel à dialética histórica como método, ainda que este se encontre com o projeto pedagógico platônico de livrar a consciência das falsas aparências da representação pelos sentidos em uma teleologia que culminaria na conjunção entre 0 belo e 0 verdadeiro, cuja inteligibilidade seria atingida pela razão. Além dessas paradoxais dobras epistemológicas entre o platonismo e 0 formalismo, este também sugere imbricações com 0 estruturalismo e a filosofia analítica, quando pensa em uma autonomia da linguagem que se produziria no texto musical e, embora Soulez (2007, p. 289) recuse a aproximação entre música e linguagem, provavelmente o faça por acreditar que "um símbolo ocupa o lugar de um conceito e não de uma palavra da linguagem natural", sugerindo uma redução da linguagem ao texto verbal.

\section{As dificuldades em assimilar $\mathbf{0}$ contexto cultural}

Adorno depara-se com o paradoxo de conceder uma autonomia à linguagem musical, sem poder livrar-se de seu contexto cultural, atravessado pela ideologia. Evidentemente, ele tem consciência que as representações sociais refletem a ideologia, mas ao lidar com conceitos, ao invés de signos, tenderia a crer que 0 idêntico 
seja apenas um atributo da condição verbal da linguagem, podendo presumir - em consonância com Nietzsche - que a música (ao menos a instrumental) exceda a determinação do conceito, tanto que chega a propor uma "distinção entre formalização e conceitualização".

A música seria, assim, um modo privilegiado de formalização daquilo que não se deixa expressar diretamente, que seria "qualitativamente contrário ao conceito". A linguagem musical diria aquilo que a linguagem prosaica não saberia dizer sem produzir determinações particulares vinculadas à indexação do mundo dos objetos (SAFATLE, 2007, p. 373).

Destarte, a música excederia a determinação do conceito. Mas novamente aqui, incide os pressupostos de que a música instrumental, desvinculada do texto verbal, estaria imune das representações sígnicas, como se estas apenas pudessem habitar a palavra ou como se, em sua organização interna a partir de materiais sonoros, a música pudesse se libertar da ideologia.

Apesar de ter em conta como uma "linguagem universal”, Adorno (2011, p. 298-302) sabe que a música "não constitui nenhum esperanto", estando sujeita a influências culturais, mas ainda nesse caso sua posição é no mínimo ambígua, pois se por um lado afirma que "quanto mais a música se converte em um idioma que se assemelha ao linguístico, tanto mais ela se move rumo às determinações nacionais", por outro lado, não há como não entrever que nessa pluralidade de culturas, ele não veja nada além de um "abominável" contágio que só pode ser "degustado como espécie de prato estrangeiro", mesmo que esse estrangeiro seja o elemento alemão para 0 gosto francês. ${ }^{2}$

Afinal, extirpar o caráter nacional da música seria como negar a dimensão estética do contexto social, por isso, Adorno (2011, p. 301) pode afirmar que "ouvir Debussy sem esse momento nacional, o qual, como resistência ao espírito alemão, constitui essencialmente 0 espírito de Debussy, não só extirparia das fibras de tal música aquilo que ela é, mas acabaria, ao mesmo tempo, por diminuí-la em si mesma", mas isso não lhe impedirá que também entenda esse nacional como uma impureza que a linguagem musical deva superar na sua busca do universal, tal como teria ocorrido com Bach e com Schoenberg.

Essa ambição pelo universal sempre foi uma característica logocêntrica como modo de remover os obstáculos epistemológicos que se apresentavam à consciência para legitimar 0 estatuto verdadeiro e autêntico do real. 0 que surpreende é que essa aspiração persista quando transladada aos sistemas de signos não verbais, como a música, que, a despeito de sua codificação, não deveria ter como horizonte um universal à revelia dos seus contextos culturais. 
A esta altura, caberia recorrer à posição de Flusser (2007, p. 58) diante das relações entre língua e realidade, quando afirma que "toda tradução é um aniquilamento" e que "[...] a legitimidade da tradução é uma função de parentesco entre as línguas", "não de um parentesco etimológico, mas de um parentesco ontológico" como aquele que existiria entre 0 grego clássico e 0 alemão moderno que permitiria antever uma similitude no modo de construir uma realidade igualmente logocêntrica. Se esta hipótese for plausível, não seria menos razoável admitir que a ideia de logos não derive apenas das línguas flexionais, mas da função que a cultura adquire nesses processos comunicacionais. 0s alemães tornaram-se possivelmente os maiores herdeiros da filosofia grega (como Nietzsche defende), não somente pela semelhança ontológica entre as línguas, mas porque sua cultura assumiu a continuidade de um projeto civilizatório, que teria se iniciado na Grécia. Ocorre que esse projeto não se esgota de modo algum na língua, mas está inscrito nos diversos sistemas de signos que se colocam em jogo na conformação de uma cultura. Portanto, se for verdadeira a insinuação de Flusser de que o pensamento alemão é herdeiro do grego por um parentesco ontológico entre as línguas, como explicar que a música teutônica possa ter se tornado um paradigma do barroco, do clássico e do modernismo, propulsionando a força de um logos que, de grego, estava por se tornar basicamente alemão, se a língua utiliza um sistema de códigos e uma gramática distintos da música? Seria possível abstrair da música suas relações promíscuas com suas formas de produção cultural, garantindo-lhe uma autonomia? Não estaria na cultura, ao invés da língua, a base dos laços de parentesco?

Ora, o próprio Adorno (2011, p. 302) considera que "a música não se torna universal mediante a abstração daquilo que ela tem de espaçotemporal em si, mas, antes, por intermédio de sua concreção", não se esgotando em "seus fatos tecnológicos", ainda que, em outras passagens, não se canse de tomar o elemento nacional como um obstáculo epistemológico a ser superado para alcançar a forma pura da linguagem musical. Ao conceder autonomia à música, o embaraço de Adorno parece ser grande, pois tem que manter a integridade da forma musical livre do contágio ideológico e, ao mesmo tempo, manter sua filiação social e isso só pode ser alcançado pensando a cultura como Bildung, como um processo de formação, de educação social, guiado pela racionalidade e pelos aspectos normativos da ética como valor universal, que culmina na construção de um projeto civilizatório.

Resulta dessa operação que a música - assim como o pensamento - "séria" seja alemã, entrevendo uma matriz cultural ao logocentrismo. Isso é válido inclusive para Nietzsche que, "após ter passado por uma epifania negativa ao se embrenhar na selva estética e teológica de Parfisal", teria dito que "Il faut méditerraniser la musique", ao apaixonar-se pela Carmen de Bizet (ROSS, 2009, p. 27), em um progressivo 
movimento de afastamento tanto da música como da filosofia germânica que se pensava herdeira da tradição logocêntrica, subvertendo sua opinião anterior em que opunha a língua alemã às românicas, e que sinalizava "para a superioridade germânica que, segundo ele, preparava 0 advento da verdadeira música" (BURNETT, 2007, p.251). Essa verdadeira música era, para Nietzsche, a música de Wagner e teria continuado a sê-la, não visse em Bayreuth uma apresentação espetacular de Parfisal que antes procurava produzir efeitos sobre a plateia do que tornar popular a verdadeira música.

Apesar das divergências, as ambições de Nietzsche são similares as de Adorno, quando pensam na cultura enquanto Bildung, e essa como germânica.

Essa arte tão superior é anunciada como um reencontro com o popular, como uma deseducação, um processo inverso àquele desencadeado por Platão, e do qual a Alemanha estaria pelas mãos de Wagner, se libertando. Por essa razão 0 drama de Wagner é também e, fundamentalmente, "supra-alemão" (überdeutsch), e está destinado aos homens do futuro (Menschen der Zunkunft) (BURNETT, 2007, p. 256).

0 atravessamento cultural e a preocupação com a recepção das audiências estão igualmente presentes nas reflexões de Adorno, quando pensa que 0 atonalismo e 0 dodecafonismo possam promover a verdadeira música em que o ouvinte comum não se reconheça, mas que exija um trabalho da consciência musical na inteligibilidade de sua estrutura. Não que Adorno não veja na música uma responsabilidade social que atinja às camadas populares afeitas ao tonal e ao sentimental, mas, ao contrário, espera - ainda que sem ilusões - que esse ouvinte possa ser educado a não mais reconhecer na música sentimentos e imagens triviais com as quais se alegra e se entretém, e sim que possa perceber uma "estrutura de sentido", não respondendo a meros estímulos. 0 que tanto Adorno como Nietzsche esperam é uma audiência que não se renda aos efeitos de espetáculo promovidos respectivamente pela indústria cultural e pela ópera de Wagner em Bayreuth, e que a nova música possa lançar o homem ao futuro, mesmo que esse futuro tenha como paradigma o passado das elites aristocráticas pré-burguesas ou o mundo grego pré-socrático.

No entanto, se a indústria cultural parece absorver todas as esperanças de superação da ideologia que impregna o signo da música e destrói a cultura, a desilusão de Nietzsche com 0 espetacular em Bayreuth o conduz a uma crítica ao romantismo alemão que se confunde com uma recusa ao logocentrismo. 0 que Nietzsche anseia é uma compreensão trágica da vida que se coloca anterior à formulação da identidade forjada do conceito, no plano em que 0 instintivo se confunde com o pré-sígnico. Adicionalmente, na medida em que se desilude com o projeto de uma "obra de arte total", universal - desde que alemã -, ele abre e enriquece 0 horizonte da música a outras paisagens sonoras que mesclam ritmos estrangeiros como os latinos. Todavia, não se pode 
disso derivar que a visão trágica da música que Nietzsche propunha tenha-se transmutado ao sabor da diversidade de sentimentos, pois estes sempre carregam representações.

[...] a "Vontade" é objeto da música, porém não a origem dela, isto é, a vontade em sua mais originária forma de aparecimento, sob a qual há que se entender todo o vir-a-ser. Aquilo que denominamos sentimentos, em vista dessa vontade, já está perpassado e saturado com representações conscientes e inconscientes, e por causa disso não é mais diretamente objeto da música: quanto menos, portanto, poderia produzi-la a partir de si mesmo. (NIETZSCHE, 2007 , p. 175, grifo do autor).

A distância epistemológica que separa Adorno de Nietzsche - assim como estão distanciadas as suas respectivas matrizes: Hegel e Schopenhauer - encurta-se na dificuldade de ambos em assimilar o contexto cultural na produção de uma música que seja universal. Essa dificuldade, que, digase, é enriquecedora da compreensão da estética musical, reside na posição ambígua que ambos mantêm diante da proposição de uma música que seja ao mesmo tempo universal, mas que recuse a identidade estabilizadora do conceito senão sua dimensão propriamente sígnica. Em Adorno, 0 formalismo surge como uma linha de fuga em que a música excede a determinação do conceito que, por sua vez, carrega as aparências sociais, enquanto, em Nietzsche, a música deve preceder as pesadas atribuições do conceito para revelar toda sua potência. Em ambos os casos, o signo aparece como obstáculo a ser superado. Seja porque se busca sua transparência que, ao fim, deve negá-lo, seja porque se pretende retroceder a um estágio em que ainda não se encontra domesticado. E assim, a música eleva-se como esse lugar privilegiado onde paradoxalmente 0 civilizado e 0 selvagem se encontram equidistantes das particularidades dos seus contextos culturais irremediavelmente medíocres.

\section{Geopolítica da música}

Como afirmamos anteriormente, as teorias estéticas são essencialmente derivadas das epistemologias dos grandes sistemas de pensamento filosófico que tendem a proposições de caráter universal e à organização dos eventos sociais em uma perspectiva linear e temporal traçada por um olhar em retrospectiva. Um sintoma claro desse procedimento ocorre quando se afirma que uma dada teoria se tornou ultrapassada, revelando sua insuficiência em dar conta de uma realidade que se modificou no tempo, como se a realidade fosse passível de uma determinação ou, ao menos, de uma condição essencialmente histórica. Embora já se admita que a presunção de universalidade que as teorias científicas carregam possa ser negada ou refutada no percurso histórico, o mesmo não ocorre em sua dimensão espacial, territorial. Admite-se que os paradigmas epistemológicos possam até ser conflitantes em sua simultaneidade e que sejam superados em sua trajetória histórica, mas os elementos dissonantes, as particularidades e as diferenças que não são absorvidas pelas teorias dominantes aparecem como resíduos ou 
ruídos que devem ser expurgados ou mantidos no constrangedor silêncio da indiferença.

As teorias estéticas refletem essa condição ao privilegiarem a localização de seus objetos de análise a partir de um contexto histórico, medido inclusive em períodos: medieval, renascentista, barroco, clássico, neoclássico, romântico, moderno; colocando em um plano secundário, senão circunstancial, sua configuração geopolítica sem ao menos traçar as devidas linhas de tensão que atravessam esses dois eixos, como se, no limite, estivessem tratando de uma cultura única, de uma Bildung que se transforma no tempo. Não se trata de mera convenção: os elementos característicos que supostamente definiriam um estilo são atribuídos ao estado da arte e ao espirito do tempo, subordinando as particularidades e os aspectos regionais a variantes desse esquema mais geral.

Assim, pode-se tanto falar em um romanticismo tardio em Mahler e Puccini, como em vanguardas, denotando a centralidade da história em suas variáveis sociais, econômicas e políticas, enquanto 0 elemento territorial em suas linhas de força geopolíticas tende a ser unicamente associado à formação dos Estados nacionais, o que nos parece uma formulação enganosa se considerarmos que a própria noção grega de política já traduz 0 esquema espacial da polis, assim como é redutora a noção de geopolítica associada à utilização de estratégias beligerantes. Portanto, a proposição de uma geopolítica da música apenas visa corrigir essa distorção que tende a desconsiderar um conjunto de forças sociais, políticas e econômicas, que se aglutina em torno do território que, por sua condição eminentemente espacial, possibilita traçar um dentro, que lhe é próprio, de um fora, que lhe é estrangeiro. 0 ocultamento dessas fronteiras territoriais implica na adoção de um pressuposto epistemológico - cuja dialética histórica é 0 principal referencial - que tende a considerar a própria dinâmica cultural como um epifenômeno do movimento histórico. Implica também em estender a proposição aristotélica do universal a inferências que, para serem logicamente aceitas, precisam ser corroboradas por seus pressupostos empíricos, de modo que não se possa afirmar a universalidade de nenhuma forma musical por imposição ideológica, mas por suas supostas qualidades intrínsecas, 0 que - diga-se de passagem - é uma missão hercúlea senão mesma fadada ao fracasso no campo estético.

Apesar de conhecedor dos meandros dessas operações epistemológicas, Adorno não raramente ultrapassa os limites dessas implicações lógicas, tecendo inferências sobre a universalidade de estilos musicais, sem explicitar seus vieses ideológicos quando assim lhe interessa. Se por um lado enfatiza o caráter universal que a música possa vir a ter, por outro admite a incidência do particular - a que chama de "nacional" - na composição dessa forma universal, ainda que saiba que, pelo movimento dialético, o universal não se constitui na soma, mas na síntese dos particulares. Nesse sentido, sua resolução parece precisa ao afirmar que: 
Se a grande música do Classicismo vienense e de seus sucessores, incluindo a segunda escola vienense, deixa-se apreender como uma ação recíproca entre 0 universal e o particular, então essa ideia Ihe foi transmitida pela reciprocidade produtiva entre as componentes alemã e italiana em Mozart. 0 universal é aquilo plenamente estabelecido e que sempre se reporta a Bach, cujo Cravo bem temperado Mozart conheceu muito bem por intermédio de Swieten; mas, segundo a linguagem da estética classicista, o particular, o elemento ingênuo do canto imediato, advém da arte do efeito dos italianos. [...] Se a grande música é integral pelo fato de não enrijecer no particular nem se submeter à totalidade, mas por deixar esta última vir à tona a partir do impulso à particularidade, então tal integração brota como eco dos momentos italiano e alemão na grandiosa linguagem musical de Mozart. Também ela recolhe em si a diferença nacional, mas trata de desenvolver respectivamente uma coisa a partir da outra, que já não é mais a mesma (ADORNO, 2011, p. 308).

0 que Adorno descreve como operação epistemológica é um processo que reporta ao conceito de Bildung que, dentro do contexto do idealismo alemão, Berman (2002, p. 80, grifo do autor) apresenta como sendo

ao mesmo tempo um processo e um resultado. Pela Bildung, um indivíduo, um povo, uma nação, uma língua, uma literatura ou uma obra de arte em geral se formam e adquirem assim uma forma, uma Bild. A Bildung é sempre um movimento em direção a uma forma que é uma forma própria.

Ainda segundo Berman (2002, p. 81-82), a Bildung constitui-se em um processo "triádico", de "um auto-processo em que há um 'mesmo' que se desdobra até adquirir sua plena dimensão" através de uma viagem (Reise) ou migração (Wanderung);

é “o movimento do 'mesmo' que, mudando, encontra-se 'outro", e também, "enquanto viagem, experiência da alteridade do mundo".

A concepção de universalidade de Adorno é extremamente coerente com a dialética histórica, mas sua aparente consonância com o processo da Bildung denota um inesperado movimento também dialético que articula o particular (0 nacional) e 0 universal (a totalidade) em uma dinâmica espacial, evidenciando as linhas de força que se colocam em movimento na configuração de um quadro geopolítico. 0 que nos parece ser equivocado supor dessa geopolítica, como manifestação de um mecanismo epistemológico, é que possa ser submetida a uma variável histórica quando Adorno articula o elemento nacional à constituição dos Estados nacionais e ao advento da sociedade burguesa.

A música mesma possui tantos elementos nacionais quanto a sociedade burguesa em geral; sua história e suas formas de organização ocorreram essencialmente dentro dos limites nacionais. Isto não foi, porém, algo extrínseco à música. Em que pese seu caráter universal - que ela deve àquilo que lhe falta frente à linguagem discursiva, a saber, a ausência de um conceito fixo -, indicava características nacionais (ADORNO, 2011, p. 299).

A imprecisão dessa variável histórica burguesa para caracterizar o elemento territorial da música é explicitada pelo próprio Adorno (2011, p. 303) quando reconhece que desde a Idade Média possam ser reconhecidos epicentros 
regionais e nacionais de música, ainda que pondere que "os estilos nacionais só se tornaram mais inteligíveis a partir da Renascença e da dissolução do universalismo medieval". Idade Média, Renascença ou Iluminismo? Supondo que aponte para um movimento progressivo e linear do elemento nacional (territorial), não seria ainda possível recuar ao menos a polis grega? Ainda mais relevante seria entender que universalismo medieval seria esse senão 0 europeu? Não estaríamos falando o tempo todo de um processo de formação de uma cultura única, de uma Bildung, que de grega, haveria de se tornar alemã?

\section{0 espírito alemão}

0 caráter alemão da música personifica-se plenamente nas figuras de Adorno e Nietzsche que, a despeito de suas orientações teóricas muito distintas, fizeram convergir pontos de vista no mesmo fascínio pela música e, particularmente, pela universalidade da música alemã. Nietzsche depositando toda sua vã esperança na transmutação pela música trágica de Wagner, que haveria de livrar a Alemanha de uma suposta decadência moral, através do espírito trágico, e Adorno, especialmente com a modernidade de Schoenberg, subvertendo as aparências de que havia já se encoberto a música romântica.

Embora admita que "o radicalismo que introduziu inovações não apenas em setores isolados como a harmonia ou a rítmica, mas que operou uma transformação radical do inteiro material composicional" tenha sido um "fenômeno centroeuropeu", incluindo Bartók e, em certa medida, Stravinsky, Adorno (2011, p. 327) reafirma que esse radicalismo repercutiu internacionalmente como uma "especialidade alemã", na mesma medida em que Schoenberg, "que construiu a música puramente a partir de si e sem levar me conta a cena mundial de então", seria, "não sem razão", "manifestação da eficiência alemã".

[...] a concepção alemã padece de hybris ${ }^{3}$, ao passo que a ocidental, de uma acomodação. Que até hoje exista uma enorme discrepância entre ambas é algo que só se deixa entender pelo fato de que, em verdade, as respectivas linguagens musicais, na medida em que se formaram no final do século XIX como linguagens nacionais, mal puderam ser corretamente compreendidas em sentido supranacional (ADORNO, 2011, p. 325).

A contraposição do elemento alemão ao "resto", ao ocidental, talvez já pudesse ser interpretada como uma manifestação dessa hybris, que em nada deixaria a desejar o espírito trágico que Nietzsche reivindicava como força destruidora e criadora do espírito grego, agora encarnado no alemão. Todavia essa universalidade - ou mais precisamente centralidade - alemã, mais uma vez, deve ser entendida como um componente vital para a proposição de uma geopolítica da música que não seria necessariamente resultado de uma condição histórica, que reuniria em torno de si 
as forças de desenvolvimento social, econômico, político ou mesmo tecnológico, mas de um sistema de signos mais amplo que não caberia nas fronteiras políticas do nacional e, provavelmente, sequer nas estruturas da língua, na medida em que a supremacia da música alemã remontaria possivelmente desde Bach até a Segunda Escola de Viena em que a sucessiva multiplicidade de contextos políticos não conseguiria ser contida em um único mapa administrativo que pudesse ser chamado de alemão.

\section{Conclusões provisórias}

Embora Adorno (2011, p.367) afirme que "a difusão e a recepção sociais da música são meros epifenômenos; a essência está na objetiva constituição social da música em si”, não se pode supor que ele pense que a partitura possa se constituir no único objeto de análise da música, contendo em si os códigos que esgotariam 0 texto musical em uma estrutura autossuficiente de sentido. Ainda que, por vezes, pareça sugerir uma análise estruturalista do texto musical, sua proposição é distinta ao supor que esses códigos reflitam ou traduzam inequivocamente a experiência social.

Que tantas pessoas se desfaçam deste momento especificamente sociológico como se fosse mero ingrediente de interpretação sociológica, considerando apenas o fato concreto da partitura como o único a constituir o objeto propriamente em questão, eis algo que não se deve fundamentalmente à música, mas à neutralização da consciência. Esta blindou a experiência musical contra a experiência daquela realidade na qual a música, por mais polêmica que seja, acha-se presente e à qual ela responde (ADORNO, 2011, p.148).

Neste sentido, não há como compreender o significado da "música séria" sem que se recorra aos conceitos de "audição estrutural" e "audição atomizada" que incorrem na questão do fetichismo, assim como se torna necessário refletir criticamente com algumas linhas gerais da noção de indústria cultural.

A título de conclusões muito provisórias, caberia pontuar que na medida em que a "música séria" não possa ser objetivada na imagem estática do texto musical (partitura), mas na dinâmica da experiência social - o que obviamente implica em atravessamento ideológico - não se pode excluir a hipótese de que a "seriedade da música" esteja ela também condicionada a variáveis históricas e geopolíticas, não podendo constituir-se em um conceito absoluto a partir do qual a música possa ser julgada em seus atributos qualitativos. Na própria Introdução à sociologia da música podemos encontrar brechas que permitem supor que a "seriedade da música" é relativa ao seu contexto histórico, na medida em que se admita como critério de distinção do que é "música séria" e do que é "música ligeira", a questão do estranhamento e do entretenimento, que, por sua vez, conduzem à distinção da audição estrutural da atomizada. Trata-se de um ponto crucial para o entendimento do que seja "música séria", pois implica em relativizar seu caráter estático e 
universal - que estaria impresso na codificação do texto musical -, ao introduzir como critério dinâmico de distinção o estranhamento que possibilitaria desestabilizar a inércia cognitiva da audição atomizada, introduzindo a diferença, 0 novo, e, portanto, reduzindo os efeitos ideológicos sobre a consciência.

Por outro lado, se a "seriedade da música" está sujeita a seu contexto histórico, também se deve admitir que se encontre condicionada a uma disposição geopolítica que organize seus próprios critérios de produção e escuta musical de modo que estes possam ser tão distintos quão distantes se encontrem de uma matriz alemã ou europeia. Ainda que 0 suposto processo de homogeneizaçãa das culturas progressivamente balize 0 gosto musical segundo os interesses da indústria cultural, a admissão das variáveis geopolíticas na reflexão estética permitiria realizar uma efetiva crítica que consistiria em buscar o não idêntico no estrangeiro através de critérios objetivos de análise, prescindindo que estes se balizem pelas noções de verdadeiro e universal.

\section{Referências}

ADORNO, Theodor W. Introdução à sociologia da música: doze preleções teóricas. São Paulo: Ed. Unesp, 2011.

Filosofia da nova música. 3. ed. São Paulo: Perspectiva, 2009.

BERMAN, Antoine. A prova do estrangeiro: cultura e tradução na Alemanha romântica. Bauru, SP:

EDUSC, 2002.
BURNETT, Henry. Nietzsche em Bayreuth. Discurso: Revista do Departamento de Filosofia da USP, n. 37, p. 217-260, 2007.

CAVALCANTI, Anna H. Música, linguagem e criação em Nietzsche. Discurso: Revista do Departamento de Filosofia da USP, n. 37, p. 183-216, 2007.

FLUSSER, Vilém. Língua e realidade. 3. ed. São Paulo: Annablume, 2007.

NIETZSCHE, F.W. El nacimiento de la tragedia. 11. ed. Madrid: Alianza Editorial, 2011. . Música e Palavra. Discurso: Revista do Departamento de Filosofia da USP, São Paulo, n. 37, p.167-182, 2007.

ROSS, Alex. 0 resto é ruído: escutando o século XX. São Paulo: Companhia das Letras, 2009.

SAFATLE, Vladimir. Fetichismo e mimesis na filosofia da música adorniana. Discurso: Revista do Departamento de Filosofia da USP, São Paulo, n. 37, p. 365-406, 2007.

SOULEZ, Antonia. Schoenberg pensador da Forma. Discurso: Revista do Departamento de Filosofia da USP, São Paulo, n. 37, p. 281-322, 2007.

VIDEIRA, Mário. Eduard Hanslick e o Belo Musical. Discurso: Revista do Departamento de Filosofia da USP, São Paulo, n. 37, p. 149-166, 2007. 
Only German music can be serious? Prelude to a geopolitics of music

\section{Abstract}

From the analysis of Adorno's formalism and Nietzsche's tragic spirit, in their theoretical considerations about the music, raises the hypothesis that they produce lines of force, immanent to the territorial and cultural context of its production and listening, drawing a geopolitical that might result in a proposition of a space matrix in order to build an aesthetic sense. What sustain such evidences are the constant inferences that these authors make to the universal character of the music contained in a presumed "German spirit", confusing their epistemological positions with the territorial boundaries of their cultures.

\section{Keywords}

Aesthetics. Epistemology. Culture.

\section{¿La música seria sólo puede ser alemana? Preludio a una geopolítica de la música}

\section{Resumen}

A partir del análisis del formalismo de Adorno y del espíritu trágico de Nietzsche, en sus consideraciones teóricas acerca de la música, se plantea la hipótesis de que estas tracen líneas de fuerza expresivas, inmanentes al contexto territorial y cultural de su producción y escucha, dibujando una geopolítica que podría resultar en la proposición de una matriz epistemológica espacial en la construcción de sentido estético. Las evidencias que apoyen esta hipótesis están en las constantes inferencias que estos autores hacen al carácter universal de la música supuestamente contenido en el "espíritu alemán", confundiendo sus posiciones epistemológicas con los límites territoriales de sus culturas.

\section{Palabras-clave}

Estética. Epistemología. Cultura. 


\section{Expediente}

A revista E-Compós é a publicação científica em formato eletrônico da Associação Nacional dos Programas de Pós-Graduação em Comunicação (Compós). Lançada em 2004, tem como principal finalidade difundir a produção acadêmica de pesquisadores da área de Comunicação, inseridos em instituições do Brasil e do exterior.
E-COMPÓS I www.e-compos.org.br I E-ISSN 1808-2599

Revista da Associação Nacional dos Programas

de Pós-Graduação em Comunicação.

E-compós, Brasilia, v.16, n.1, jan./abr. 2013

A identificação das edições, a partir de 2008,

passa a ser volume anual com três números.

\section{CONSELHO EDITORIAL}

Afonso Albuquerque, Universidade Federal Fluminense, Brasil Alberto Carlos Augusto Klein, Universidade Estadual de Londrina, Brasil Álvaro Larangeira, Universidade Tuiuti do Paraná, Brasil André Luiz Martins Lemos, Universidade Federal da Bahia, Brasil Ângela Freire Prysthon, Universidade Federal de Pernambuco, Brasil Angela Cristina Salgueiro Marques, Faculdade Cásper Líbero (São Paulo), Brasil Antonio Roberto Chiachiri Filho, Faculdade Cásper Líbero, Brasil Arthur Autran Franco de Sá Neto, Universidade Federal de São Carlos, Brasil Benjamim Picado, Universidade Federal Fluminense, Brasil César Geraldo Guimarães, Universidade Federal de Minas Gerais, Brasil Cristiane Freitas Gutfreind, Pontifícia Universidade Católica do Rio Grande do Sul, Brasil

Denilson Lopes, Universidade Federal do Rio de Janeiro, Brasil Eduardo Peñuela Cañizal, Universidade Paulista, Brasil

Eduardo Vicente, Universidade de São Paulo, Brasil Eneus Trindade, Universidade de São Paulo, Brasil Erick Felinto de Oliveira, Universidade do Estado do Rio de Janeiro, Brasil Florence Dravet, Universidade Católica de Brasília, Brasil Gelson Santana, Universidade Anhembi/Morumbi, Brasil Gislene da Silva, Universidade Federal de Santa Catarina, Brasil Guillermo Orozco Gómez, Universidad de Guadalajara Gustavo Daudt Fischer, Universidade do Vale do Rio dos Sinos, Brasil Hector Ospina, Universidad de Manizales, Colômbia Herom Vargas, Universidade Municipal de São Caetano do Sul, Brasil Inês Vitorino, Universidade Federal do Ceará, Brasil Jay David Bolter, Georgia Institute of Technology Jeder Silveira Janotti Junior, Universidade Federal de Pernambuco, Brasil John DH Downing, University of Texas at Austin, Estados Unidos José Afonso da Silva Junior, Universidade Federal de Pernambuco, Brasil José Carlos Rodrigues, Pontifícia Universidade Católica do Rio de Janeiro, Brasil José Luiz Aidar Prado, Pontifícia Universidade Católica de São Paulo, Brasil Kelly Cristina de Souza Prudêncio, Universidade Federal do Paraná, Brasil.
Laan Mendes Barros, Universidade Metodista de São Paulo, Brasil Lance Strate, Fordham University, USA, Estados Unidos Lorraine Leu, University of Bristol, Grã-Bretanha Lucia Leão, Pontifícia Universidade Católica de São Paulo, Brasil Malena Segura Contrera, Universidade Paulista, Brasil

Márcio de Vasconcellos Serelle, Pontifícia Universidade Católica de Minas Gerais, Brasil

Maria Aparecida Baccega, Universidade de São Paulo e Escola Superior de Propaganda e Marketing, Brasil

Maria Ataide Malcher, Universidade Federal do Pará, Brasil

Maria das Graças Pinto Coelho, Universidade Federal do Rio Grande do Norte, Brasil Maria Immacolata Vassallo de Lopes, Universidade de São Paulo, Brasil Maria Luiza Martins de Mendonça, Universidade Federal de Goiás, Brasil Mauro de Souza Ventura, Universidade Estadual Paulista, Brasil Mauro Pereira Porto, Tulane University, Estados Unidos Mirna Feitoza Pereira, Universidade Federal do Amazonas, Brasil Nilda Aparecida Jacks, Universidade Federal do Rio Grande do Sul, Brasil Osvando J. de Morais, Universidade de Sorocaba, Brasil Potiguara Mendes Silveira Jr, Universidade Federal de Juiz de Fora, Brasil Renato Cordeiro Gomes, Pontifícia Universidade Católica do Rio de Janeiro, Brasil Robert K Logan, University of Toronto, Canadá

Ronaldo George Helal, Universidade do Estado do Rio de Janeiro, Brasil Rose Melo Rocha, Escola Superior de Propaganda e Marketing, Brasil Rossana Reguillo, Instituto de Estudos Superiores do Ocidente, Mexico Rousiley Celi Moreira Maia, Universidade Federal de Minas Gerais, Brasil Sebastião Guilherme Albano da Costa, Universidade Federal do Rio Grande do Norte, Brasil

Simone Maria Andrade Pereira de Sá, Universidade Federal Fluminense, Brasil Tiago Quiroga Fausto Neto, Universidade de Brasília, Brasil Suzete Venturelli, Universidade de Brasília, Brasil Valerio Fuenzalida Fernández, Puc-Chile, Chile

Veneza Mayora Ronsini, Universidade Federal de Santa Maria, Brasil Vera Regina Veiga França, Universidade Federal de Minas Gerais, Brasil

\section{COMISSÃO EDITORIAL}

Adriana Braga I Pontifícia Universidade Católica do Rio de Janeiro, Brasil

Felipe Costa Trotta I Universidade Federal Fluminense, Brasil

CONSULTORES AD HOC

Bruno Campanella, Universidade Federal Fluminense, Brasil

Christa Berger, Universidade do Vale do Rio dos Sinos, Brasil

Edison Gastaldo, Universidade Federal Rural do Rio de Janeiro, Brasil

José Luiz Braga, Universidade do Vale do Rio dos Sinos, Brasil

\section{EDIÇÃO DE TEXTO E RESUMOS I Susane Barros}

SECRETÁRIA EXECUTIVA I Juliana Depiné

EDITORACã̃ ELETRÔNICA I Roka Estúdio
COMPóS I www.compos.org.br

Associação Nacional dos Programas de Pós-Graduação em Comunicação

Presidente

Julio Pinto

Pontifícia Universidade Católica de Minas Gerais, Brasil juliopinto@pucminas.br

Vice-presidente

Itania Maria Mota Gomes

Universidade Federal da Bahia, Brasil

itania@ufba.br

Secretária-Geral

Inês Vitorino

Universidade Federal do Ceará, Brasil

inesvic@gmail.com 